\title{
The Influenza Vaccination and Neurological Complications
}

Key words: influenza vaccine, acute disseminated encephalomyelitis, Guillain-Barré syndrome

Epidemics or pandemics of influenza occur every winter season; and in elderly patients in particular the high mortality is attributable to the complication of bacterial pneumonia. In addition, fatal influenza A or B virus-associated encephalitis/encephalopathy has increased in Japan since 1990 in children, and even in adults (1-3). The influenza vaccine is the most effective means of preventing influenza (4), and the inactivated influenza vaccine (HA) used presently in Japan is believed to be safe. Generalized adverse reactions such as shock or fever are rare, although there have been a few local responses, such as localized swelling or pain. These generalized reactions are limited mainly to children.

In this issue, Nakamura et al (5) reported two elderly patients who suffered neurological complications after the influenza vaccination; one with acute disseminated encephalomyelitis (ADEM) and the other with myelitis with acute motor axonal neuropathy, similar to Guillain-Barré syndrome (GBS). Although these side effects mostly involve children, they claimed that neurological complications from influenza vaccinations could occur in adults and in the elderly.

See also p 191.

With regards to the side effects of the influenza vaccination, the association between GBS and the administration of the Swine influenza vaccination in 1976/1977 are well known $(6,7)$. The incidence of GBS due to A/New Jersey/76 was annually 2.31 per 100,000 recipients, in which the primary cause was the vaccine strain. Subsequently, Lasky et al (8) reported an occurrence of 1-2 per million recipients from 1992 to 1994. In Japan, the occurrence was 1 per 7 million people.

Neurological complications aside from GBS are rare. ADEM or myelitis with axonal neuropathy after the influenza vaccination has been limited to a few patients $(9,10)$. With the progress of magnetic resonance imaging and other tools, the diagnoses of ADEM or myelitis are more likely to be made, and reports of these complications may increase.

The influenza vaccine must be administered every year, and the side effects should be minimal; however, death due to influenza vaccination is extremely rare, considering death due to influenza itself. Between 1972 and 1995, the death rate due to influenza was estimated to be 300 to 1,500 per a million in elderly people over 65 years (11). The side effects of the influenza vaccination are fewer than other vaccinations, and the vaccine is superior in terms of safety. The efficacy and cost benefit are recognized throughout the world, and the vaccine is widely recommended for high risk groups such as elderly people over 65 years, and patients with chronic diseases (12).

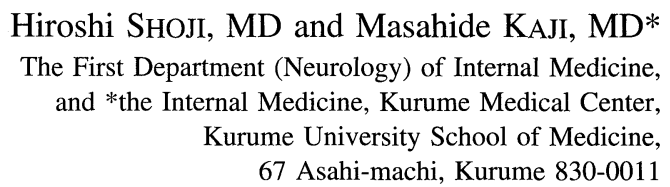

\section{References}

1) Okabe N, Yamashita K, Taniguchi $K$, Inouye S. Influenza surveillance system of Japan and acute encephalitis and encephalopathy in the influenza season. Pediatr Int 42: 187-191, 2000.

2) Togashi $T$, Matsuzono $Y$, Narita M. Epidemiology of influenzaassociated encephalitis-encephalopathy in Hokkaido, the northernmost island of Japan. Pediatr Int 42: 192-196, 2000.

3) Iijima $\mathrm{H}$, Wakasugi $\mathrm{K}$, Ayabe $M$, Shoji $\mathrm{H}$, Abe $\mathrm{T}$. An adult case of influenza A virus-associated encephalitis: magnetic resonance imaging findings. J Neuroimaging 12: 273-275, 2002.

4) Govaert TM, Thijs CT, Masurel N, Sprenger MJ, Dinant GJ, Knottnerus JA. The efficacy of influenza vaccination in elderly individuals. A randomized double-blind placebo-controlled trial. JAMA 272: 1661-1665, 1994.

5) Nakamura N, Nokura K, Zettsu T, et al. Neurologic complications associated with influenza vaccination: two adults cases. Intern Med 42: 191-194, 2003.

6) Fenichel GM. Neurological complications of immunization. Ann Neurol 12: 119-128, 1982.

7) Safranek TJ, Lawrence DN, Kurland LT, et al. Reassessment of the association between Guillain-Barré syndrome and receipt of swine influenza vaccine in 1976-1977: Results of a two-state study. Expert Neurology Group. Am J Epidemiol 133: 940-951, 1991.

8) Lasky T, Terracciano GJ, Magder L, et al. The Guillain-Barré syndrome and the 1992-1993 and 1993-1994 influenza vaccines. N Engl J Med 339: 1797-1802, 1998.

9) Saito H, Endo M, Takase S, Itahara K. Acute disseminated encephalophlomyelitis after influenza vaccination. Arch Neurol 37: 564-566, 1980.

10) Miyamoto M, Katayama S, Miyamoto T, Hirata K, Ichimaru Y. ADEM following influenza vaccination. A case report. Shinkeinaika 44: 179182, 1996 (in Japanese).

11) Prevention and control of influenza: Recommendations of the advisory committee on immunization practices (ACIP). MMWR Morb Mortal Wkly Rep 47 (RR-6): 1-3, 1998.

12) Prevention and control of influenza: Recommendations of the advisory committee on immunization practices (ACIP). MMWR Morb Mortal Wkly Rep 51 (RR-3): 6-10, 2002. 